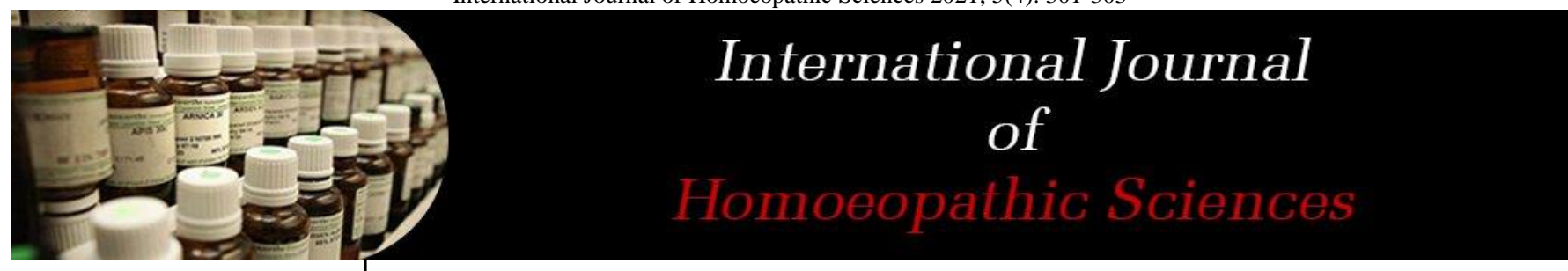

E-ISSN: $2616-4493$ P-ISSN: 2616-4485 www.homoeopathicjournal.com IJHS 2021; 5(4): 301-303

Received: 03-08-2021

Accepted: 21-09-2021

Dr. Munazza Shaikh MD Homeopathy Scholar, Practice of Medicine, Guru Mishri HMC, Jalna, Maharashtra, India

Dr. Rashmi Desarda Guru Mishri HMC, Jalna, Maharashtra, India
Corresponding Author: Dr. Munazza Shaikh MD Homeopathy Scholar, Practice of Medicine, Guru Mishri HMC, Jalna, Maharashtra, India

\section{Migraine and homoeopathic management}

\author{
Dr. Munazza Shaikh and Dr. Rashmi Desarda
}

DOI: https://doi.org/10.33545/26164485.2021.v5.i4e.488

\section{Abstract}

Migraine is an extremely common symptom and collectively migraine disorders are among the most common of the nervous system disorders, with a prevalence of $48.9 \%$ in the general population.1 Migraine affects people of all ages, races and socioeconomic status and is more common in women. Some migraines are extremely debilitating and have significant impact on an individual's quality of life, imposing huge costs to healthcare and indirectly to the economy in general. Only a small proportion of migraine disorders require specialist input. The vast majority can be effectively treated by a primary care physician or generalist with correct clinical diagnosis that requires no special investigation. Primary migraine disorders - migraine, tension headache and cluster headache constitute nearly $98 \%$ of all migraines; however, secondary migraines are important to recognise as they are serious and may be life threatening. This article provides an overview of the most common migraine disorders and discusses the red flag symptoms that help identify serious causes that merit urgent specialist referral. The current pathway of migraine care in the UK is discussed with a view to proposing a model that might fit well in the financially constrained National Health Service (NHS) and with new NHS reforms. The role of the national society, the British Association for the Study of Migraine, and the patient organisations such as Migraine Trust in migraine education to the professionals and the general public in shaping migraine care in the UK is described. The article concludes by summarising evidence-based management of common migraine diagnoses.

Keywords: Migraine, headache, tension headache, cluster headache, medication overuse headache

\section{Introduction}

Migraine is a common symptom often associated with disability but rarely life threatening. Most common reason for patient consultation in the general neurology at least $20 \%$ are accounting of all consultations.

\section{Approach to the patients of Migraine}

First step is to distinguish serious from benign etiologies.

Intensity of headaches rarely has diagnostic value.

Migraine location can suggest involvement of local structures.

Provocation by environmental factors suggests a benign cause.

\section{Etiopathology}

Migraine results from stimulation/pressure of any of the pain sensitive structures of the head (All Tissues Covering Cranium, 5th, 9th, 10th cranial nerves, The Upper Cervical Nerve, Large Intracranial Venous Sinuses, Large Arteries At Base Of Brain, Dural arteries, Dura matter of the skull base).

Dilatation or contraction of blood vessel walls stimulates nerve endings causing headache.

\section{Classification}

Acute headache-Sudden in onset, resent origin.

Chronic headache-occurs gradually and lasts for long period.

Types of acute headaches

Meningitis and other infectious causes

Acute, most commonly seen

Whole cranial pain

Severe Migraine associated with fever, photophobia stiffness of neck

Subarachnoid headache 
Most commonly seen acute headache with meningeal irritation

Space occupying lesions

Subacute progressive Migraine

\section{Primary headaches}

Migraine: Headache that lasts 4 to 72 hrs, throbbing, moderate to severe in intensity, is unilateral becomes worse with exertion and associated with nausea vomiting or photophobia or phonophobia. May be associated with focal disturbances

Pathophysiology of migraine- Related to neurovascular dysfunction, Dilatation of blood vessels innervated by the trigeminal nerve caused by release of neuropeptides from parasympathetic nerve fibers.

Familial hemiplegic migraine (FHM): Autosomal dominant Mutation of 3 associated genes -ATP1A2, CACNA1A, SCINA.

Basilar artery migraine: A uncommon variantAssociated with blindness or visual disturbances throughout both visual fields. Also called as menstrual migraine, since it's commonly seen in females.

Accompanied by dysarthria, dysequilibrium, tinnitus and periodical and distal paraesthesias, transient loss or impairment of consciousness or confessionals state.

Tension headache: Most common type of primary headache disorder Pericranial bilateral Headache lasts 30 min to 7 days and is nonpulsating, bandlike discomfort Mild to moderate in severity, builds slowly, Not aggravated by exertion and not associated with nausea, vomiting, or sensitivity to light, sound or smell.

Management: Along with therapeutic approach treatment for co-morbid anxiety or depression is important.

Techniques to induce relaxation are useful include;

Massage, Hotbaths, Biofeedback: Is a process that enables an individual to learn how to change physiological activity for the purposes of improving health and performance.

Precise instruments measure physiological activity such as brainwaves, heart function, breathing, muscle activity, and skin temperature.

These instruments rapidly and accurately 'feed back' information to the user.

The presentation of this information-often about changes in thinking, emotions, and behaviour-supports desired physiological changes. Over time, these changes can endure without continued use of an instrument.

Cluster Headache (Suicidal Headache): Headache lasts for 15 to $180 \mathrm{~min}$ ( $3 \mathrm{hrs}$ ), is severe, is unilateral is located periorbitally or retroorbital occurs upto 8 times per day, Attacks may last for 4 to 8 weeks

Associated at least with the following

Tearing pain with recurrent episodes

Conjunctival congestion, unilateral lachrymation

unilateral nasal congestion, rhinorrhoea, Facial sweating, Ptosis, meiosis and anhidrosis (horner syndrome), unlike migraine, patient tend to move about during attacks, Core feature is periodicity.

Triggering factors- Alcoholism, Stress, glare, Ingestion of specific food

Trigeminal neuralgia (tic douloureux): Causes unilateral lancinating facial pains

Severe and repetitive pains

Precipitated by touching triggering zones within trigeminal territory or by eating.

Tendency of relapse over the years.

Management- Pharmacological

Surgical treatment should be considered when response is in complete in young patients

Decompression of the vascular loop on the trigeminal roots (90\% success rate).

\section{Causes of Migraine in}

Intracranial extra cranial systemic

Arteriovenous malformation

Benign intracranial hypertension

Brain abcess

Encephalitis

Intracerebral hematoma

Meningitis

Subarachnoid hemorrhage

Subdural hematoma

Stroke

vasculitis

Cervical spine disorders

Dental disorders

Giant cell arteritis

Glaucoma

Optic neurtitis

Sinusitis

TMJ disorders

Anemia

Caffeine withdrawal

Fever

Hypercapnia

Hypertension

Hypoxia

Vasoactive chemicals

Viremia

\section{Post traumatic Migraine}

Nonspecific symptoms may follow closed head injury Positional Headache appears within a day following injury, may worsen over weeks and gradually subsides.

Lumbar puncture migraine: Typical onset within $48 \mathrm{hrs}$ after lumbar puncture

Seen in $10-30 \%$ patients

Onset when patient sits or stands,

Relief by lying flat; Mostly remit < 1week.

Dull throbbing headache is frequently seen in case of lumbar puncture may last for several weeks.

Migraine is commonly due to leakage of cerebrospinal fluid through dural puncture site.

Migraine due to intracranial lesions- Migraine caused due to displacement of vascular structures and other pain sensitive tissues

\section{Evaluation of Migraine in general Complete neurological examination}

If examination is abnormal or serious underlying cause is 
suspected, an imaging study (CT/MRI) is indicated Lumbar puncture is required when meningitis is suspected.

Psychological state of the patient should also be evaluated because a relationship exists between pain and depression. Electronystagmogram suggests either peripheral or central vestibulopathy. (Is a diagnostic test to record involuntary movements of eyes caused by nystagmus. Also detects the lesion is in eyes, inner ear, brain.)

\section{Homoeopathic approach}

Some of the common remedies in homoeopathy that could be used in our daily practice for these varieties of migraine according to their symptom similarity are as follows.

Natrummur: Throbbing pain, pain as if thousand hammers were knocking on the brain, in the morning on awakening, after menses, from sunrise to sunset, with pale face, nausea and vomiting, periodical. <during menses.

Bryonia: Headache with nausea, bursting, splitting type, sensation as if everything would be pressed out, as if hit by a hammer from within, headache settles in occiput <motion even of eye balls.

Belladona: Throbbing pain with fullness especially in forehead, also occiput and temples. Pain < light, noise, lying on right side, in afternoon $>$ pressure, semierrect.

Iris versicolor- Frontal headache with nausea. Scalp feels constricted. Right temples affected, begins with a blurring of vision, a/f mental stress, <rest.

Glonine: $\mathrm{A} / \mathrm{F}$ sunstroke, heat, artificial lights; Throbbing headache, head feels large as if skull were too small for brain, sun headache, increases and decreases with sun. Headache in place of menses > uncovering head.

Spigellia: Pain beneath frontal eminence and temples extending to eyes, unilateral, involving left eye. Pain is violent, throbbing, pain as if a band around the head.

\section{References}

1. Longo Dan L, Fauci Anthony S, Kasper Dennis L et al. Harrison's principles of internal medicine $19^{\text {th }}$ edition.

2. Porter Robert S, Justin Kaplan L. The Merck manual 19th edition.

3. Colledge Nicki R, Walker Brian R, Ralston Stuart H. Davidson's principles and practice of medicine. Adi BS. Efficacy of homoeopathic medicines in chronic low back pain: a clinical study. International Journal of Alternative and Complementary Medicine. $21^{\text {st }}$ edition, 2020, 17-20.

4. Coles AJ, Larner AJ, Solding NJ, Barker RA. A-Z of neurological practice-a guide to clinical neurology.

5. Papadakis Maxine A, McPhee Stephen J, Rabow Michael W. Current medical diagnosis and treatment, 54th edition, Publisher: McGraw-Hill Education, 2015.

6. Boerickewilliam Pocket manual of homoeopathic material medical with repertory, B Jain Publishers, $(\mathrm{P})$ Ltd, new Delhi.

7. https://migraine.com/migraine-types/basilarmigraine/www.medscape.com/ 